\title{
Prereview for "Parasitologia desenhada: uma ferramenta auxiliar no aprendizado de discentes do curso de medicina veterinária"
}

\author{
Andreia Weiss ${ }^{1}$ \\ ${ }^{1}$ Affiliation not available
}

July 20, 2020

Resumo: Este é um Grupo de Revisores de pré-impressão da Revista Ensino \& Pesquisa. O texto avaliado foi "Parasitologia desenhada: uma ferramenta auxiliar no aprendizado de discentes do curso de medicina veterinária", de Isabella Vilhena Freire Martins, Jankerle Neves Boeloni,Josileia curty de oliveira, cíntia das Chagas Bernardo ( DOI: 10.22541/au.159406482.27359109)

O artigo das autoras Isabella Vilhena Freire Martins, Jankerle Neves Boeloni, Josileia Curty de Oliveira e Cíntia das Chagas Bernardo, apresenta a proposta de metodologia - jogo didático desenvolvido na disciplina de Parasitologia Veterinária, ofertada no $3^{\mathrm{o}}$ período do Curso de Medicina Veterinária da UFES - Campus de Alegre.

A revisão bibliográfica está constituída em diferentes autores e comentadores sobre a utilização de jogos e sua possibilidade de ser utilizada e ampliada para o ensino superior. No decorrer da revisão bibliográfica algumas questões são destacadas pelas autoras como a perspectiva de utilizar ferramentas e/ou metodologias diferenciadas que diferem do processo tradicional do ensino - aprendizagem, que seria as metodologias ativas (BORGES; ALENCAR, 2014; ROSA, 2017; MACEDO et al., 2018). E, no caso, definem o jogo como uma possibilidade nesse processo, evidenciando a ludicidade como ponto para o interesse por parte do aluno pelo conteúdo que está sendo ministrado, buscando autores que desenvolveram pesquisas nesse sentido na Medicina Veterinária (ALMEIDA et al., 2012; BRAGAGNOLLO et al., 2019; PIZUTTI et al., 2018). No decorrer da mesma, apresentam os autores Melo, Avila e Santos (2017) e Covos et al. (2018) para compreender a relação entre o jogo lúdico e o processo de ensino - aprendizagem.

Para tanto, esclarecem que a pesquisa se configurou como qualitativa e o jogo didático intitulado "Parasitologia Desenhada", inspirada num jogo comercial (Imagem \& Açãoß), se baseou em um dos conteúdos que compreende a Disciplina Parasitologia Veterinária que são as características morfológicas dos parasitos. O referido jogo foi aplicado durante nove (9) anos para nove (9) turmas de alunos do $3^{0}$ período do referido curso, totalizando 441 alunos participantes. O jogo prevê a interação entre o grupo para chegar ao fim proposto e, todos os membros do grupo tem sua vez de ser o responsável pelo registro da imagem para que seu grupo possa identificar o parasita a que se refere.

As autoras analisam que esse jogo possibilita a interação entre docente e discentes, evidenciando o processo de motivação e compreensão do que foi pontuado no jogo com o conteúdo ministrado na disciplina. Por fim concluem que a utilização do jogo é possível, estimulador e se configura em um caminho para se trabalhar no Ensino Superior.

\section{Ponderações quanto ao artigo:}

O artigo possui relevância e possibilita o olhar para o processo de ensino - aprendizagem pelo método de 
trabalho em grupo - jogo. Algo valido e necessário de ser discutido e disponibilizado.

Todavia, após a análise do mesmo, sugiro que alguns pontos necessitam ser revistos pelas autoras:

1) revisão bibliográfica: o artigo apresenta alguns autores e comentadores que são utilizados para referendar o uso dos jogos didáticos e sua relação com o processo de ensino-aprendizagem, no entanto, o mesmo não possui um teórico que de corpus ao processo de ensino e aprendizagem e/ou das metodologias ativas. Dessa forma, é importante que as autoras vislumbrem esse teórico que fundamenta esses dois elementos oque, por sua vez, irá auxiliar no item "resultados e discussão";

2) os jogos e/ou atividades que estimulam o lado lúdico do conteúdo é utilizado com mais frequência em outros cursos/áreas do conhecimento, no entanto, estes estão sendo visualizado como uma possibilidade na Medicina Veterinária (explicar e explorar essa possibilidade, tendo em vista que é o curso foco do artigo). Isso é necessário até para compreender que somente a fixação não dá conta do processo de aprendizagem (o que é defendido pelas autoras quanto estas esclarecem que as metodologias tradicionais deixam a desejar no processo de ensino-aprendizagem);

3) resultados e discussão: a realização da estratégia possui pontos interessantes e permite vislumbrar outra possibilidade de estratégia de ensino para o ensino, no entanto, seria importante a) analisar o processo da aplicação do jogo com os autores e o teórico que fundamenta o processo de ensino-aprendizagem e a metodologia ativa. Assim, o leitor compreenderá quais foram os desafios e as descobertas com essa ferramenta. Cuidar para não trazerem elementos que no decorrer da discussão ficam sem serem explicadas ou relacionadas com o objeto do artigo; b) apresentar e analisar como foi o processo da avaliação que o docente realizou no decorrer da aplicação da ferramenta, pois no $5^{\underline{0}}$ parágrafo da página n. 8 começa a ser mencionado que "[...] foi possível avaliar a aprendizagem e a memorização [...]".

4) Por fim, sugiro rever a relação e/ou o encadeamento das ideias entre as frases e os parágrafos, pois em alguns momentos, as ideias estão "cortadas" / fragmentadas sem a articulação e coerência necessária. 